3 Research S Suare

\title{
Geometric Accuracy and Mechanical Behavior of Polymer-Based Composite Curved Tubes produced by Fused Filament Fabrication (FFF)
}

Asma Boumedine

Khaled Benfriha

Mohammad Ahmadifar

Samir Lecheb

Mohammadali SHIRINBAYAN ( $\square$ mohammadali.shirinbayan@ensam.eu )

Arts et Metiers ParisTech

Abbas Tcharkhtchi

Research Article

Keywords: FFF, mechanical properties, dimensional stability

Posted Date: April 8th, 2021

DOl: https://doi.org/10.21203/rs.3.rs-331882/v1

License: (a) (i) This work is licensed under a Creative Commons Attribution 4.0 International License.

Read Full License 


\section{Abstract}

The present study aims to assess and characterize the effect of processing parameters including infill pattern and reinforcement type on the dimensional accuracy of products manufactured by Fused Filament Fabrication (FFF) process as well as on the mechanical properties of the printed components. The reinforcements used were carbon, Kevlar and glass fibers supplied by MarkForged $\circledast$; they were utilized to manufacture the PA6 matrix composite. The mechanical properties of the stated composites were compared. Finally, the results obtained confirmed that the selection of the appropriate type of the reinforcements and infill patterns among the several available types during the printing process is effective in improving the mechanical properties and also in providing a better geometrical quality of the surfaces and the consequent dimensional precision improvement of the parts printed by FFF process.

\section{Introduction}

Additive manufacturing (AM) [1-2], 3D printing and prototyping [3][4], or solid freeform fabrication [5], are all instances of a layer-by-layer manufacturing process in which parts are manufactured from designed geometries [6]. Given modern technological progress, AM is gaining popularity, which can make it a common manufacturing process [7]. This approach has provided many benefits; it can improve flexibility and convenience, reduce manufacturing costs and reduce turnout time for multiple manufacturing applications $[8,9]$.

One of the main and effective advantages of AM is the geometric flexibility, which allows the assembly of the complex parts without increasing the manufacturing costs [8-10]. The successful implementation and expansion of AM requires the improvements in the surface quality, shear and durability, accuracy and precision of these processes [11]. In these issues, surface quality, accuracy and precision are the main obstacles, which don't let AM to be presented and considered as a primary production process $[10,12]$.

In AM we distinguish several methods to manufacture parts such as, selective laser melting, laserengineered net shaping, 3D welding, laminated object manufacturing. Various materials have been developed in polymer printing, which are specific to the used AM techniques [11]. For instance, for selective laser sintering we have powder materials [12], and for polyjet and stereolithography we have liquid photopolymers $[13,14]$, thermoplastic polymer are developed for Fused Deposition Modeling (FDM) process [15].

Fused Filament Fabrication (FFF) technology is based on manufacturing the parts from computer aided design (CAD) data by fusing a superposition of thin coils of filament through a heated nozzle, in form of layer-by-layer [16]. The filament is deposited layer by layer until the whole desired component is formed [17]. The used raw material in the form of filament could be thermoplastic polymers such as polypropylene (PP), acrylonitrile butadiene styrene (ABS), polyethylene (PE) or polylactic acid (PLA). polycarbonate $(\mathrm{PC})$, polyamide (PA or Nylon), polyetherimide (PEI), polyetheretherketone (PEEK) and etc [18]. 
Most of the industries are looking for stronger and lighter materials. Therefore, polymer matrix composites (PMCs) have been studied by many researchers [19], as they can achieve the suitable thermomechanical properties when the appropriate reinforcement is used to reinforce the polymer matrix [20]. For more than a decade study and research on the improvement and development of composite materials for AM processes has been ongoing [21]. However, as some polymers cannot reach the required mechanical properties through AM, FDM manufacturing process of polymer matrix composites (PMCs) are developed to obtain composite-based structural components with satisfactory mechanical properties for specific applications $[22,23]$. This method was successfully implemented by MarkForged $\AA$. In fact, the continuous fiber reinforcement has been introduced into the 3D geometry via the double extrusion method [24-30].

Lately composite materials have been designed and manufactured for several applications and have been introduced as common type of engineering materials. It is understood that the composite tubes have the potential to replace even the metal products on many applications. High attention is directed to producing the composite tubes and the consequent characterizations [31].

The influence of the infill pattern on mechanical properties of FDM manufactured components has been studied by many researchers due to the existence of many suggested and available patterns. In fact, it has been proven that selecting the suitable infill pattern is an important step in producing 3D geometries. The effects of percentage infill and infill patterns on the tensile strength of printed ABS parts were investigated by Fernandez-Vicente et al. [32] : the maximum tensile strength was reported to be around 36.6 MPa related to an infill percentage of $100 \%$ in a rectilinear configuration. The effects of infill patterns on the cost and strength of the printed components have been studied by Baich et al. [33]; many types of infill patterns, including solid, high, low, and double dense were considered. The solid-samples presented the maximum tensile, flexural, and compressive strengths and also modulus. Akhoundi et al. [34] investigated experimentally the effect of infill pattern on tensile and flexural strength and modulus of parts printed via FFF. Their selected conditions were infill percentages of 20,50 , and $100 \%$ and also the different types of infill patterns including rectilinear, concentric, hilbert curve and honeycomb. According to the results obtained the concentric pattern presented the required flexural and tensile behaviours at all the stated infill percentages [35].

FFF printed parts have presented poor mechanical property issues which arise from weak bonding and adhesion between the printed layers, minor discontinuities in the extrusion of filament, also the existence of shrinkage which is uncontrolled during the cooling process, etc. [36-38].

It is stated that, the control of the required dimensional accuracy is a significant issue for the application of FDM process in direct manufacturing [39-40]. Multiple variation sources can cause shape deviation and inaccuracy of AM components in comparison with the desired and designed shapes. Several research studies on optimization of the required geometric accuracy of the manufactured parts via FDM processes have been conducted. According to the Bochmann et al. [41] investigation, it is stated that the magnitude of the errors significantly varied in the $x, y$ and $z$ directions in FFF process, which can influence 
the accuracy, precision, and quality of final surface. El-Katatny et al. [42] measured and analyzed the error obtained in geometric characteristics of determined sections on anatomical parts which have been manufactured by FDM method. A methodology of spectral graph theory was used by Tootooni et al. $[43,44]$ and Rao et al. $[45]$ in order to quantify and evaluate the geometric precision of FFF parts using the deviations of the 3D point cloud coordinate measurements from the specifications of the design. It was clarified that the proposed indicator did not propose a relationship or correlation between the geometric precision and the process parameters, but only facilitated the comparison of the geometric precision of the parts. Statistical analysis of dimensional accuracy based on the Taguchi method and artificial neural network (ANN) Sood et al. [46]optimized processing parameters including layer thickness, part orientation and raster angle in FFF. Saqib et al. [47] reported that the geometry of an object affects the accuracy more than processing parameters in FFF process. Also, the perpendicularity and flatness features of geometries could influence the accuracy of the printed components. Chang et al. [48] found that profile errors and extruding apertures are two essential quality factors which need to be taken into account via FFF process. Also the accuracy depends on transmission machinery and filament diameter.

The mechanical properties of the manufactured parts can be significantly improved by the suitable adjustment of the process parameters obtained from the conducted research. It is understood that there is a clear relationship between the selected and excerpted parameters and the obtained mechanical properties of the manufactured part. Optimization of process parameters has significantly attracted the attention of different researchers, such as filling velocity (Ning et al. 2016) [49], diameter of the nozzle used, envelope temperature (Sun et al. 2008) [50], raster angle (Chockalingam et al. 2016) [51], layer thickness (Lee et al. 2005, Wu et al. 2015, Tian et al. 2016) [52-53-54], road width (Anitha et al. 2001, Duigou et al. 2016) [55-56], raster gap (Mohamed et al. 2016) [57], temperature of extrusion (Garg and Singh 2016, Boparai et al. 2016a) [58-59]. All these parameters should be controlled to achieve a suitable part quality with satisfactory mechanical properties.

This study assesses and characterizes the influence of the process parameters including material type and the selected infill pattern on the dimensional accuracy, as well as on the mechanical properties of the parts manufactured by FFF process. A compression test was applied on the PA6 reinforced with carbon, Kevlar and glass fibers composites under uniform conditions and the mechanical performance of all three composite types are compared.

\section{Material Description, 3d Printer Device And Characterization Methods}

\subsection{Raw Material: polyamide 6 (PA 6)}

The material used as raw material was polyamide 6 (PA 6). It is introduced as one of the newest matrix materials for fabricating the composite parts with Markforged 3D printers. The Isotropic fiber fill type made of Carbon, Glass and Kevlar was chosen as the reinforcement printing type. The printed model for 
this study was a tube with height, thickness, and external diameter of $50 \mathrm{~mm}, 4 \mathrm{~mm}$, and $40 \mathrm{~mm}$, respectively (Fig. 1).

\subsection{D printer device}

One of the Markforged desktop printers, is Mark Two Printer which was used in this study (Fig. 2). This printer was used to print parts from Nylon 6 supplied by Markforged. It alows reinforcing parts with continuous carbon, glass or Kevlar fibers.

The nylon 6 was printed with a temperature of $273^{\circ} \mathrm{C}$ and fiber layers were printed with a temperature of $232^{\circ} \mathrm{C}$, on a non-heated printer bed platform. The carbon fiber was printed in layer height value of 0.125 $\mathrm{mm}$, and the Kevlar and glass fibers used were printed with a layer height of $0.1 \mathrm{~mm}$. The dual extrusion system allows continuous fiber reinforcement to be placed as the required and determined layers. Also this possibility is provided to specify the fiber orientation in the component during the deposition process. Eiger ${ }^{\circledR}$ is the designated software for MarkTwo, which makes it possible to import OBJ and STL models.

Mark Two has ability to produce different structures at different percentages. According to the related printer software, it is possible to choose three main types of infill pattern, which are rectangular, triangular and hexagonal. Also, during our study, we considered the solid infill status as another structure or infill pattern. In fact, in the solid fill pattern, the raster orientations of the layers were $+45^{\circ},-45^{\circ}$. Concentric and isotropic are the fiber patterns that could be selected in the Markforged Mark Two desktop 3D printer.

Moreover, two types of specimens were considered: unreinforced and continuous reinforced nylon specimens. The printing conditions for the polymer(polyamide-6) samples were: $37 \%$ of fill density for the triangular and rectangular, hexagonal fill patterns, 4 roof and layers (the number of layers of solid plastic are used on the top and bottom of the part) and 2 wall layers (the thick of the walls of the part). More walls will make a pure plastic part stronger, but will also reduce the area that fiber will be able to fit into). For the solid fill pattern the density was 100\% with 2 wall layers. For Nylon full reinforced (Carbon, Glass, and Kevlar) specimens were printed with solid fill pattern ,100\% fill density and 4 roof and layers, 2 wall layers. The total fiber layers was 490 (the total number of layers filled with fibers) with a concentric fiber fill type (the fiber fill type determines the algorithms which control how fiber will be used to reinforce the part). All the walls were reinforced (inner holes and outer shell), and 2 concentric fiber rings (the number of rings of concentric fiber fill added per layer).

\subsection{Characterization methods}

\subsubsection{Geometric accuracy measurement}

A desktop 3D laser scanner (Solutionix D500) was used to scan the geometry and obtain point-by-point coordinate measurements of the component, referred to as a 3D point cloud. The laser scanner records reflected light from the part surface as a point in the 3D space, with a maximum volumetric deviation. Solutionix D500 is powered by Solutionix ezScan. The program is used to calibrate devices, as well as 
process scan data stitch images taken from different sides at different angles. The desktop rotates scanned objects from different angles. A ray of blue light bounces off objects and enters camera lenses.

For dimensional and quality control a professional 3D Geomagic ${ }^{\circledR}$ Control $X^{\mathrm{TM}}$ software was used, which captures and processes data from 3D scanners. It makes possible calculation of geometric deviations by comparing the data from the point cloud with the original computer aided design (CAD model). The calculation procedure consists of several steps. The alignment of the measured scan to the CAD requires a careful part alignment procedure to achieve consistent results. The alignment step requires matching at least four points of the raw point cloud data to the CAD model and subsequent analysis, each of which has its own literature [36, 37]

\subsubsection{Quasi-static compression test}

The sample used was according to Fig. 1. Quasi-static compression experiments were achieved with the INSTRON 5966 machine, the loading cell of $50 \mathrm{kN}$, and the loading speed used was $5 \mathrm{~mm} / \mathrm{min}$. The special jaws were designed to perform the compression tests and the tubes were positioned between two jaws as sketched in Fig. 3. In order to ensure reproducibility of the results, at least three samples were created in the compression test study.

\section{Dimensional Accuracy And Mechanical Properties Relation}

The tubes were printed using the nylon 6 filament and continuous fibers, under the main stated fill patterns. Then they were analyzed for the geometric accuracy. Finally the tubes were tested in compression loading. The comparison with the compression strength of the different patterns and also with the solid pattern, for which fill percentage was $100 \%$ was carried out. So, the compression strength was considered as the criterion to make the comparison.

\subsection{Effect of infill patterns}

This part treats three important parameters; the first parameter is the choice of materials; we used a polymer (Polyamide 6) and also composites; nylon (PA 6) reinforced with three types of fibers which are: Carbon fiber, Glass fiber and Kevlar. The second parameter is infill pattern: triangular, and rectangular, hexagonal, solid. These parameters were varied to investigate which parameter affects the dimensional accuracy the most and what are the more appropriate for a better print quality and high precision accuracy.

Geometric accuracy results for nylon with different fill patterns; triangular, rectangular, hexagonal, and solid are presented in Figure. 4. One can see that the parts (specimens) are deformed inwards which is known as the shrinkage phenomenon and with different amplitudes (Figs. 5 and 6). The rectangular fill pattern is less deformed comparing with triangular, hexagonal and solid ones. One can note that from 10 $\mathrm{mm}$ to $40 \mathrm{~mm}$ of height of tube for all fill patterns, there is homogenous deformation.At the initial time of printing (from 0 to $10 \mathrm{~mm}$ of height) the First layers can exchange temperature in all directions, and the 
ending time of printing (from 40 to $50 \mathrm{~mm}$ of height) last layers which can also exchange with air but also receives heat exchange from previous layers.

Moreover, an increasing gap with retraction of each layer and also the retraction of the lower layer which will add up is significant (Fig. 7).

The compression test results for the different infill pattern samples, which were made of nylon 6 are presented in Fig. 8. According to comparison between the effect of the different infill patterns in the case of compression strength, the solid infill pattern had the highest strength which was about $52.37 \pm 3.5$ $\mathrm{MPa}$. Then the compression strength was decreased by changing the infill pattern from the solid infill to Hexagonal, Triangular, and Rectangular. The related compression strengths of the printed specimens with the infill patterns of Hexagonal, Triangular, and Rectangular were $51.02 \pm 5 \mathrm{MPa}, 28.73 \pm 0.5 \mathrm{MPa}$, and $23.42 \pm 2.3 \mathrm{MPa}$, respectively (Fig. 9). In fact, by changing the infill pattern from solid infill to Hexagonal infill, the compression strength was decreased by about $2.58 \%$. But, in the case of the infill pattern change from Solid to Triangular and Solid to Rectangular, the compression strength was decreased by about $45.14 \%$ and $55.28 \%$ respectively. 


\begin{tabular}{|c|c|c|c|c|c|}
\hline \multicolumn{6}{|c|}{ Unreinforced Rectangular infill pattern } \\
\hline \multirow[t]{2}{*}{ Sample } & $\mathrm{E}$ & $\sigma_{\max }$ & $\varepsilon_{\max }$ & $\sigma_{y}$ & $\varepsilon_{\mathrm{y}}$ \\
\hline & $\mathrm{MPa}$ & $\mathrm{MPa}$ & $\mathrm{mm} / \mathrm{mm}$ & $\mathrm{MPa}$ & $\mathrm{mm} / \mathrm{mm}$ \\
\hline 1 & 365 & 21.8 & 0.08 & 16.3 & 0.05 \\
\hline 2 & 430 & 26.1 & 0.08 & 19.9 & 0.05 \\
\hline 3 & 480 & 22.4 & 0.04 & 15.6 & 0.02 \\
\hline Average & 425 & 23.4 & 0.07 & 17.3 & 0.04 \\
\hline STDEV & 57.7 & 2.3 & 0.03 & 2.3 & 0.01 \\
\hline \multicolumn{6}{|c|}{ Unreinforced Hexagonal infill pattern } \\
\hline \multirow[t]{2}{*}{ Sample } & E & $\sigma_{\max }$ & $\varepsilon_{\max }$ & $\sigma_{y}$ & $\varepsilon_{\mathrm{y}}$ \\
\hline & $\mathrm{MPa}$ & $\mathrm{MPa}$ & $\mathrm{mm} / \mathrm{mm}$ & $\mathrm{MPa}$ & $\mathrm{mm} / \mathrm{mm}$ \\
\hline 1 & 755 & 53.9 & 0.102 & 43.4 & 0.06 \\
\hline 2 & 710 & 53.9 & 0.103 & 44.9 & 0.065 \\
\hline 3 & 650 & 45.2 & 0.1 & 35 & 0.057 \\
\hline Average & 705 & 51.1 & 0.102 & 41.2 & 0.061 \\
\hline STDEV & 52.7 & 5.1 & 0.002 & 5.4 & 0.004 \\
\hline \multicolumn{6}{|c|}{ Unreinforced Triangular infill pattern } \\
\hline \multirow[t]{2}{*}{ Sample } & E & $\sigma_{\max }$ & $\varepsilon_{\max }$ & $\sigma_{y}$ & $\varepsilon_{\mathrm{y}}$ \\
\hline & $\mathrm{MPa}$ & $\mathrm{MPa}$ & $\mathrm{mm} / \mathrm{mm}$ & $\mathrm{MPa}$ & $\mathrm{mm} / \mathrm{mm}$ \\
\hline 1 & 410 & 29 & 0.149 & 23.4 & 0.06 \\
\hline 2 & 410 & 29.1 & 0.149 & 23.4 & 0.06 \\
\hline 3 & 390 & 28.2 & 0.180 & 19.3 & 0.05 \\
\hline Average & 403 & 28.8 & 0.159 & 21.9 & 0.057 \\
\hline STDEV & 11.6 & 0.52 & 0.018 & 2.4 & 0.004 \\
\hline \multicolumn{6}{|c|}{ Unreinforced Solid infill pattern } \\
\hline \multirow[t]{2}{*}{ Sample } & E & $\sigma_{\max }$ & $\varepsilon_{\max }$ & $\sigma_{y}$ & $\varepsilon_{\mathrm{y}}$ \\
\hline & $\mathrm{MPa}$ & $\mathrm{MPa}$ & $\mathrm{mm} / \mathrm{mm}$ & $\mathrm{MPa}$ & $\mathrm{mm} / \mathrm{mm}$ \\
\hline 1 & 750 & 55.1 & 0.094 & 47.3 & 0.066 \\
\hline
\end{tabular}




\begin{tabular}{|llllll|}
\hline \multicolumn{7}{|c|}{ Unreinforced Rectangular infill pattern } \\
\hline $\mathbf{2}$ & 760 & 53.6 & 0.097 & 39.9 & 0.56 \\
\hline $\mathbf{3}$ & 680 & 48.4 & 0.096 & 39.3 & 0.062 \\
\hline Average & 730 & 52.4 & 0.096 & 42.2 & 0.229 \\
\hline STDEV & 43.5 & 3.5 & 0.002 & 4.4 & 0.286 \\
\hline
\end{tabular}

Figure 8. Compression results for nylon with different infill patterns

One can notice that the rectangular infill pattern has minimum compression properties; however after geometric accuracy results it presents minimum deformation. The latter can be explained by the relation time of the polymer used. Cooling speed of the filament for different infills can be another reason.

The temperature selection is highly dependent on the viscosity of the polymer and should be adjusted with the right printing speed; too high temperature may cause a reduction in the polymer viscosity and the melt will become too fluid and highly flowable which result in a lot of plastic leaking out from the hot end (nozzle) during printing, and reducing the dimensional accuracy. Otherwise when the temperature is too low, the new layer will simply not stick to the previous layer and the surface of the thread could be a bit rough [50].

\subsection{Effect of reinforcement type}

The geometric accuracy results for composite specimens (Fig. 10) shows different deformations. The printed PA 6 reinforced with carbon fiber composite is deformed outwards (dilatation) contrary to Kevlar and glass fiber which are deformed inwards (shrinkage). Also, Kevlar is more deformed in the first layers. As the graph shows the deformation of the reinforced tube with Kevlar and glass fiber is almost the same. The results showed different part behaviors after the FFF process, and the deformation of measured parts (3D models) changed with the variation of reinforcement. It is important to take into account the reinforcement filament thickness: carbon fiber was printed with a layer height value of 0.125 $\mathrm{mm}$, and the Kevlar and glass fibers were printed with a layer height of $0.1 \mathrm{~mm}$, so it is logical to obtain this significant difference in deformation.

According to comparison between the compression strength of reinforced Solid infill pattern (perpendicular to the applied stress direction) by different type of the used reinforcements, the glass reinforcement had the highest strength which was about 52.7 $\pm 2.84 \mathrm{MPa}$. Then the compression strength was decreased by altering the glass fibers with Kevlar and carbon fibers. The related compression strength of the reinforced solid infill pattern by the glass, Kevlar and carbon reinforcement perpendicular to the applied stress direction, were $52.7 \pm 2.84 \mathrm{MPa}, 51.99 \pm 2.95 \mathrm{MPa}$, and $49.1 \pm 1.04 \mathrm{MPa}$, respectively (according to the Figs. 11 and 12). In fact, the compression strength of the reinforced Nylon (solid infill pattern) by carbon fibers was decreased by altering with Kevlar and carbon fibers about $1.3 \%$ and $6.8 \%$, respectively. 


\begin{tabular}{|c|c|c|c|c|c|}
\hline \multicolumn{6}{|c|}{ Reinforced by Carbon Fiber } \\
\hline \multirow[t]{2}{*}{ Sample } & $\mathrm{E}$ & $\sigma_{\max }$ & $\varepsilon_{\max }$ & $\sigma_{y}$ & $\varepsilon_{\mathrm{y}}$ \\
\hline & $\mathrm{MPa}$ & $\mathrm{MPa}$ & $\mathrm{mm} / \mathrm{mm}$ & $\mathrm{MPa}$ & $\mathrm{mm} / \mathrm{mm}$ \\
\hline 1 & 740 & 47.9 & 0.094 & 32.2 & 0.045 \\
\hline 2 & 690 & 50 & 0.106 & 39 & 0.059 \\
\hline 3 & 690 & 49.4 & 0.095 & 36.8 & 0.056 \\
\hline Average & 706 & 49.1 & 0.098 & 36 & 0.053 \\
\hline STDEV & 28.8 & 1 & 0.007 & 3.5 & 0.007 \\
\hline \multicolumn{6}{|c|}{ Reinforced by Glass Fiber } \\
\hline \multirow[t]{2}{*}{ Sample } & $\mathrm{E}$ & $\sigma_{\max }$ & $\varepsilon_{\max }$ & $\sigma_{y}$ & $\varepsilon_{\mathrm{y}}$ \\
\hline & $\mathrm{MPa}$ & $\mathrm{MPa}$ & $\mathrm{mm} / \mathrm{mm}$ & $\mathrm{MPa}$ & $\mathrm{mm} / \mathrm{mm}$ \\
\hline 1 & 690 & 49.9 & 0.094 & 41.1 & 0.063 \\
\hline 2 & 750 & 52.7 & 0.099 & 40.2 & 0.056 \\
\hline 3 & 720 & 55.5 & 0.113 & 41.9 & 0.06 \\
\hline Average & 720 & 52.7 & 0.102 & 41.1 & 0.060 \\
\hline STDEV & 30 & 2.8 & 0.010 & 0.9 & 0.003 \\
\hline \multicolumn{6}{|c|}{ Reinforced by Kevlar Fiber } \\
\hline \multirow[t]{2}{*}{ Sample } & $\mathrm{E}$ & $\sigma_{\max }$ & $\varepsilon_{\max }$ & $\sigma_{y}$ & $\varepsilon_{\mathrm{y}}$ \\
\hline & $\mathrm{MPa}$ & $\mathrm{MPa}$ & $\mathrm{mm} / \mathrm{mm}$ & $\mathrm{MPa}$ & $\mathrm{mm} / \mathrm{mm}$ \\
\hline 1 & 730 & 54.1 & 0.099 & 42.3 & 0.059 \\
\hline 2 & 770 & 53.3 & 0.0902 & 42.6 & 0.057 \\
\hline 3 & 700 & 48.6 & 0.125 & 37.3 & 0.055 \\
\hline Average & 733 & 52 & 0.105 & 40.7 & 0.057 \\
\hline STDEV & 35 & 2.9 & 0.019 & 3 & 0.002 \\
\hline
\end{tabular}

Figure 12. The effect of the different reinforcements on the compression strength (reinforcing, perpendicular to the stress direction)

One can note that the nylon reinforced with carbon fiber has minimum compression properties in comparison to kevlar and glass fibers. 


\subsection{Macroscopic observation}

One can observe from Fig. 13, the shape of the specimens after compression test which were produced by solid infill pattern. The rectangular was found to be damaged more significantly in macroscopic observations.

The cooling rate of the specimens through the printing process is affected by the movement of the extrusion head temperature (which is higher than the envelope temperature), as a consequence it will influence the adhesion and bonding between the adjacent deposited filament [49]

The use of various materials in a dedicated and optimized system may change its standard melt rheological behavior requirement, thereby influencing the melt processes. Therefore, many parameters need to be adjusted in order to obtain the best quality for the final product.

\section{Conclusion}

In this study, the assessment of the influence of the process parameters including material and infill pattern on the dimensional accuracy and precision, as well as on the mechanical properties of components manufactured by FDM process, were examined. This involves the manufacturing of polymer matrix composites (PMCs) with carbon, Kevlar and glass fibers reinforcements, provided by MarkForged $\AA$. Then the compression performance of the manufactured composites were evaluated and compared. The reinforcements and the infill patterns make it possible to improve the mechanical behavior while also obtaining a better geometrical quality and precision of the FDM manufactured parts.

\section{Declarations}

\section{Authors' contributions}

1. Benfriha, M. Shirinbayan, A. Tcharkhtchi: construct the idea. A. Boumedine, K. Benfriha, M. Ahmadifar, S. Lecheb, M. Shirinbayan, A. Tcharkhtchi: analyzed results, draft manuscript preparation, and wrote the paper. M. Shirinbayan: correct the English and the paper format.

\section{Availability of data and materials}

The authors declare that the data and the materials of this study are available within the article.

\section{Declarations}

- Ethical approval: All procedures performed in studies involving human participants were in accordance with the ethical standards of the institutional and/or national research committee and with the 1964 Helsinki declaration and its later amendments or comparable ethical standards.

- Consent to participate: Informed consent was obtained from all individual participants included in the study. 
- Consent to publish: The participants have consented to the submission of the case report to the journal.

- Conflict of interest: The authors declare no competing interests.

\section{References}

[1] Huang, Y., Leu, M. C., Mazumder, J., and Donmez, A., 2015, "Additive Manufacturing: Current State, Future Potential, Gaps and Needs, and Recommendations," ASME J. Manuf. Sci. Eng., 137(1), p. 014001.

[2] Kruth, J. P., Leu, M. C., and Nakagawa, T., 1998, "Progress in Additive Manufacturing and Rapid Prototyping," CIRP Ann. Manuf. Technol., 47(2), pp. 525-540.

[3] Levy, G. N., Schindel, R., and Kruth, J. P., 2003, "Rapid Manufacturing and Rapid Tooling With Layer Manufacturing (LM) Technologies, State of the Art and Future Perspectives," CIRP Ann. Manuf. Technol., 52(2), pp. 589-609.

[4] Sachs, E., Cima, M., Williams, P., Brancazio, D., and Cornie, J., 1992, "Three Dimensional Printing: Rapid Tooling and Prototypes Directly From a CAD Model," ASME J. Manuf. Sci. Eng., 114(4), pp. 481-488.

[5] Hague, R., Mansour, S., and Saleh, N., 2004, "Material and Design Considerations for Rapid Manufacturing," Int. J. Prod. Res., 42(22), pp. 4691-4708.

[6] Crawford, R. H., and Beaman, J. J., 1999, “Solid Freeform Fabrication,” IEEE Spectr., 36(2), pp. 34-36.

[7] C.K. Chua, K.F. Leong, C.S. Lim, Rapid prototyping: principles and applications, World Scientific,2010.

[8] Bourell D, Leu M and Rosen D 2009 Roadmap for additive manufacturing-identifying the future of freeform processing (The University of Texas at Austin Laboratory for Freeform Fabrication Advanced Manufacturing Center).

[9] Levy G, Schindel R and Kruth J-P 2003 Rapid manufacturing and rapid tooling with layer manufacturing (LM) technologies, state of the art andfuture perspectivesCIRP Ann. 52 589-609.

[11] Sood A, Ohdar R and Mahapatra S 2009 improving dimensional accuracy of fused deposition modeling processed part using grey taguchi method Mater. Des. 30 4243-52.

[10] Bochmann, L., Bayley, C., Helu, M., Transchel, R., Wegener, K., \& Dornfeld, D. (2015). Understanding error generation in fused deposition modeling. Surface Topography: Metrology and Properties, 3(1), 014002. doi:10.1088/2051-672x/3/1/014002

[11] G.D. Goh, S. Agarwala, G.L. Goh, V. Dikshit, S.L. Sing, W.Y. Yeong, Additive manufacturing in unmanned aerial vehicles (UAVs): Challenges and potential, Aerospace Science and Technology 63 (2017) 140-151. 
[12] M.S. Wahab, K.W. Dalgarno, B. Cochrane, Synthesis of Polymer Nanocomposites for Selective Laser Sintering(SLS), Journal of Mechanics Engineering and Automation 1(2) (2011) 100-107.

[13] A. Sakly, S. Kenzari, D. Bonina, S. Corbel, V. Fournée, A novel quasicrystal-resin composite for stereolithography, Materials \& Design 56 (2014) 280-285.

[14] H. Yang, J.C. Lim, Y. Liu, X. Qi, Y.L. Yap, V. Dikshit, W.Y. Yeong, J. Wei, Performance evaluation of ProJet multi-material jetting 3D printer, Virtual and Physical Prototyping 12(1) (2017) 95-103.

[15] M.F. Afrose, S.H. Masood, P. lovenitti, M. Nikzad, I. Sbarski, Effects of part build orientations on fatigue behaviour of FDM-processed PLA material, Progress in Additive Manufacturing (2015) 1-8.

[16]. Mohamed, OA.; Masood, SH.; Bhowmik, JL. Optimization of fused deposition modeling process parameters: a review of current research and future prospects. Advances in Manufacturing 2015, doi:10.1007/s40436-014-0097-7, 3, 42-53.

[17]. Gebhardt A. Understanding Additive Manufacturing. Munich: Carl Hanser Verlag GmbH \& Co. KG; 2012.

[18] S.S. Yao, F.L. Jin, K.Y. Rhee, D. Hui, S.J. Park, Recent advances in carbon fiberreinforced thermoplastic composites: a review, Composites: Part B 142 (2018) 241-250

[19] C. González, J. J. Vilatela, J. M. Molina-Aldareguía, C. S. Lopes, and J. LLorca, (2017) "Structural composites for multifunctional applications: Current challenges and future trends," Prog. Mater. Sci., vol. 89, pp. 194-251.

[20] S. A.P., S. P.S., and S. K. Narayanankutty, (2017) “Electrical, thermal, mechanical and electromagnetic interference shielding properties of PANI/FMWCNT/TPU composites," Prog. Org. Coatings, vol. 113, 168174.

[21] N. Mohan, P. Senthil, S. Vinodh, N. Jayanth, A review on composite materials and process parameters optimisation for the fused deposition modelling process, Virtual and Physical Prototyping 12(1) (2017) 47-59.

[22] Karsli NG, Aytac A. Tensile and thermomechanical properties of short carbon fiber reinforced polyamide 6 composites. Composites Part B: Engineering. 2013;51:270-75.

[23] Botelho E. Mechanical behavior of carbon fiber reinforced polyamide composites. Composites Science and Technology. 2003;63:1843-55.

[24] G.W. Melenka, B.K.O. Cheung, J.S. Schofield, M.R. Dawson, J.P. Carey, Evaluation and prediction of the tensile properties of continuous fiber-reinforced 3D printed structures, Compos. Struct. 153 (2016) 866-875. 
[25] A.N. Dickson, J.N. Barry, K.A. McDonnell, D.P. Dowling, Fabrication of continuous carbon, glass and kevlar fibre reinforced polymer composites using additive manufacturing, Addit. Manuf. 16 (2017) 146152

[26] J. Justo, K. Tavara, L. Garcia-Guzman, F. Paris, Characterization of 3D printed long fibre reinforced composites, Compos. Struct. 185 (2018) 537-548.

[27] F. van der Klift, Y. Koga, A. Todoroki, M. Ueda, Y. Hirano, R. Matsuzaki, 3D printing of continuous carbon fibre reinforced thermo-plastic CFRTP tensile test specimens, Open J. Compos. Mater. 6 (2016) $18-27$.

[28] G. Dong, Y. Tang, D. Li, Y.F. Zhao, Mechanical properties of continuous kevlar fiber reinforced composites fabricated by fused deposition modeling process, Procedia Manuf. 26 (2018) 774-781.

[29] H. Al Abadi, H.-T. Thai, V. Paton-Cole, V.I. Patel, Elastic properties of 3D printed fibre-reinforced structures, Compos. Struct. 193 (2018) 8-18.

[30] J.M. Chacón, M.A. Caminero, Additive manufacturing of continuous fiber reinforced thermoplastic composites using fused deposition modelling: Effect of process parameters on mechanical properties, Composites Science and Technology 181 (2019) 107688.

[31] Abdewi, E. F., Sulaiman, S., Hamouda, A. M. S., \& Mahdi, E. (2008). Quasi-static axial and lateral crushing of radial corrugated composite tubes. Thin-Walled Structures, 46(3), 320-332.

[32]Fernandez-Vicente M, Calle W, Ferrandiz S, Conejero A (2016)Effect of infill parameters on tensile mechanical behavior in desktop3D printing. 3D Print Add Manufact 3(3):183-192

[33]Baich L, Manogharan G, Marie H (2015) Study of infill print designon production cost-time of 3D printed ABS parts. Int J RapidManuf 5(3-4):308-319

[34]Akhoundi, B., \& Behravesh, A. H. (2019). Effect of Filling Pattern on the Tensile and Flexural Mechanical Properties of FDM 3D Printed Products. Experimental Mechanics.

[35] J.M. Chacón, M.A. Caminero, E. García-Plaza, P.J. Nuñez, Additive manufacturing of PLA structures using fused deposition modelling: effect of process parameters on mechanical properties and their optimal selection, Mater. Des. 124 (2017) 143-157

[36] G. Liao, Z. Li, Y. Cheng, D. Xu, D. Zhu, S. Jiang, J. Guo, X. Chen, G. Xu, Y. Zhu, Properties of oriented carbon fiber/polyamide 12 composite parts fabricated by fused deposition modeling, Mater. Des. 139 (2018) 283-292.

[37] M. Ivey, G.W. Melenka, J.P. Carey, C. Ayranci, Characterizing short-fiber-reinforced composites produced using additive manufacturing, Adv. Manuf. Polym. Compo. Sci. 3 (2017) 81-91. 
[38] G Ćwikła1 , C Grabowik2, The influence of printing parameters on selected mechanical properties of FDM/FFF 3D-printed parts . IOP Conf. Series: Materials Science and Engineering 227 (2017) 012033

[39] Navangul, G., Paul, R., and Anand, S., 2013, "Error Minimization in Layered Manufacturing Parts by Stereolithography File Modification Using a Vertex Translation Algorithm," ASME J. Manuf. Sci. Eng., 135(3), p. 031106.

[40] Huang, Q., Nouri, H., Xu, K., Chen, Y., Sosina, S., and Dasgupta, T., 2014, “Predictive Modeling of Geometric Deviations of 3D Printed Products-A Unified Modeling Approach for Cylindrical and Polygon Shapes," Finalist of Best Application Paper, the Tenth IEEE International Conference on Automation Science and Engineering (CASE 2014), Taipei, Taiwan, AUg. 18-22, pp. 25-30.

[41] Bochmann, L., Bayley, C., Helu, M., Transchel, R., Wegener, K., and Dornfeld, D., 2015, “Understanding Error Generation in Fused Deposition Modeling," Surf. Topogr.: Metrol. Prop., 3(1), p. 014002.

[42] El-Katatny, I., Masood, S. H., and Morsi, Y. S., 2010, “Error Analysis of FDM Fabricated Medical Replicas," Rapid Prototyping J., 16(1), pp. 36-43.

[43] Tootooni, M. S., Dsouza, A., Donovan, R., Rao, P., Kong, Z., and Borgesen, P., 2017, “Assessing the Geometric Integrity of Additive Manufactured Parts From Point Cloud Data Using Spectral Graph Theoretic Sparse Representation-Based Classification," ASME Paper No. MSEC2017-2794.

[44] Tootooni, M. S., Dsouza, A., Donovan, R., Rao, P., Kong, Z., and Borgesen, P., 2017, “Classifying the Dimensional Variation in Additive Manufactured Parts From Laser-Scanned Three-Dimensional Point Cloud Data Using Machine Learning Approaches," ASME J. Manuf. Sci. Eng., 139(9), p. 091005

[45] Rao, P. K., Kong, Z., Duty, C. E., Smith, R. J., Kunc, V., and Love, L. J., 2015, “Assessment of Dimensional Integrity and Spatial Defect Localization in Additive Manufacturing Using Spectral Graph Theory," ASME J. Manuf. Sci. Eng., 138(5), p. 051007.

[46]. Sood, A.K., R.K. Ohdar, and S.S. Mahapatra, Improving dimensional accuracy of Fused Deposition Modelling processed part using grey Taguchi method. Materials \& Design, 2009. 30(10): p. 4243-4252.

[47]. S, S. and U. J, An Experimental Study to Determine Geometric and Dimensional Accuracy Impact Factors for Fused Deposition Modelled Parts. Reconfigurable and Virtual Production, 2011.

[48]. Chang, D. and B. Huang, Studies on profile error and extruding aperture for the RP parts using the fused deposition modeling process. The International Journal of Advanced Manufacturing Technology, 2010. 53(9-12): p. 1027-1037.

[49] Ning, F., et al., 2016. Additive manufacturing of carbon fiber reinforced plastic composites using fused deposition $58 \mathrm{~N}$. MOHAN ET AL. modelling: effects of process parameters on tensile properties. Journal of Composite Materials. 
[50]Sun, Q., et al., 2008. Effect of processing conditions on the bonding quality of FDM polymer filaments. Rapid Prototyping Journal, 14 (2), 72-80.

[51] Chockalingam, K., Jawahar, N., and Praveen, J., 2016. Enhancement of anisotropic strength of fused deposited ABS parts by genetic algorithm. Materials and Manufacturing Processes, 31 (15), 2001-2010.

[52] Lee, B.H., et al., 2005. Optimization of rapid prototyping parameters for production of flexible ABS object. Journal of Materials Processing Technology, 169, 54-61.

[53] Wu, W., et al., 2015. Influence of layer thickness and raster angle on the mechanical properties of 3Dprinted PEEK and a comparative mechanical study between PEEK and ABS. Materials, 8 (9), 5834-5846.

[54] Tian, X., et al., 2016. Interface and performance of 3D printed continuous carbon fibre reinforced PLA composites. Composites Part A: Applied Science and Manufacturing, 88, 198-205.

[55] Anitha, R., Arunachalam, S., and Radhakrishnan, P., 2001. Critical parameters influencing the quality of prototypes in fused deposition modelling. Journal of Material Processing Technology, 118 (1-3), 385388.

[56] Duigou, A.L., et al., 2016. 3D printing of wood fibre bio composites: from mechanical to actuation functionality. Materials and design, 96, 110-114.

[57]Mohamed, O.A., Masood, S.H., and Bhowmik, J.L., 2016. Experimental investigations of process parameters influence on rheological behaviour and dynamic mechanical properties of FDM manufactured parts. Materials and Manufacturing Processes, 31 (15), 1983-1994.

[58] Garg, H., and Singh, R., 2016. Investigations for melt flow index of Nylon6-Fe composite based hybrid FDM filament. Rapid Prototyping Journal, 22 (2), 338-343.

[59] Boparai, K.S., Singh, R., and Singh, H., 2016b. Wear behaviour of FDM parts fabricated by composite material feed stock filament. Rapid Prototyping Journal, 22 (2), 350-357.

\section{Figures}




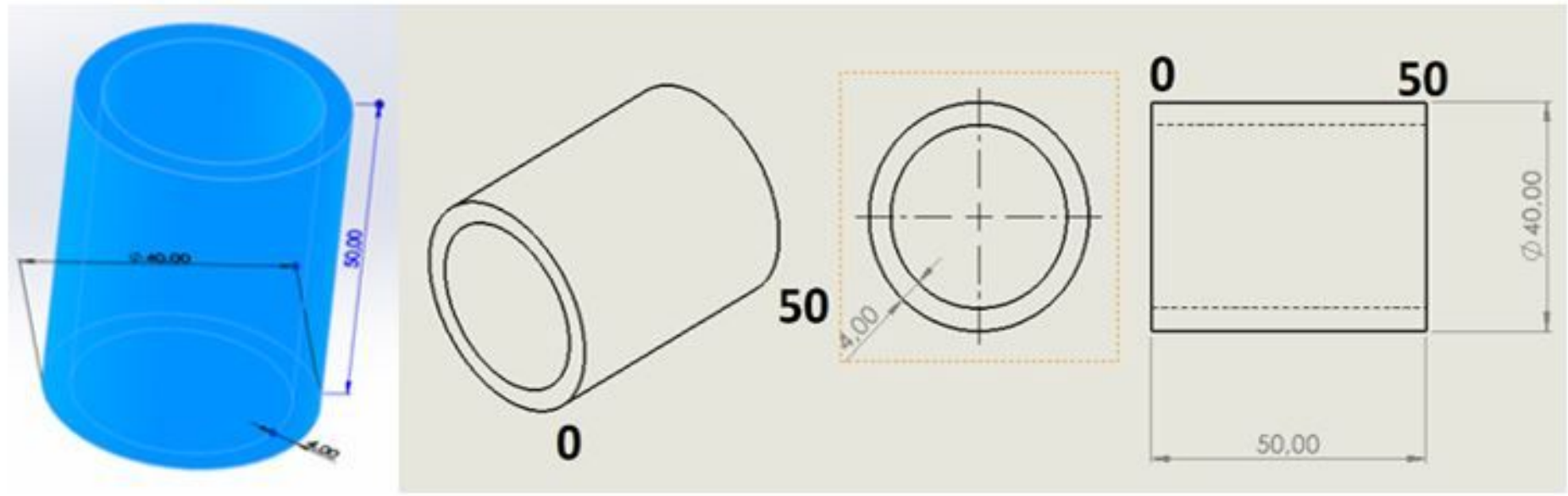

Figure 1

The dimensions of the printed tube
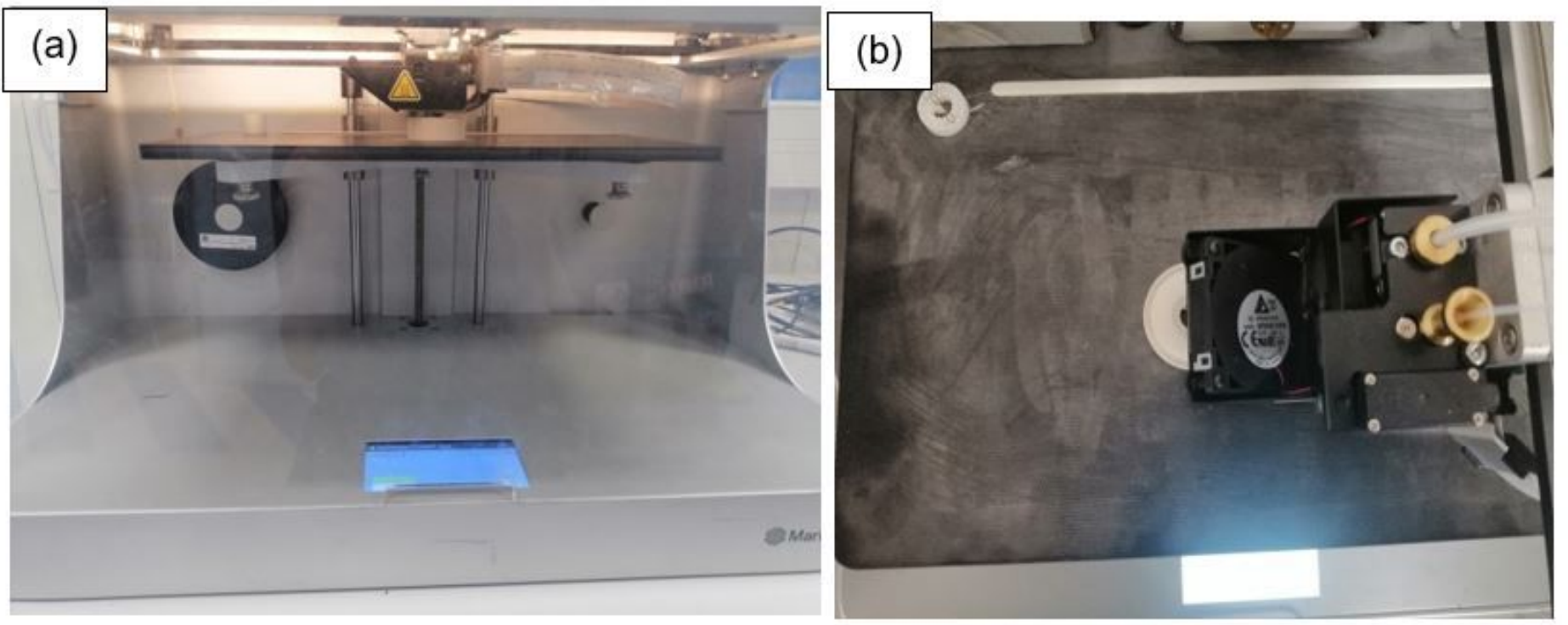

Figure 2

Mark Two printer (a) and printer during the printing of the required specimens (b) 


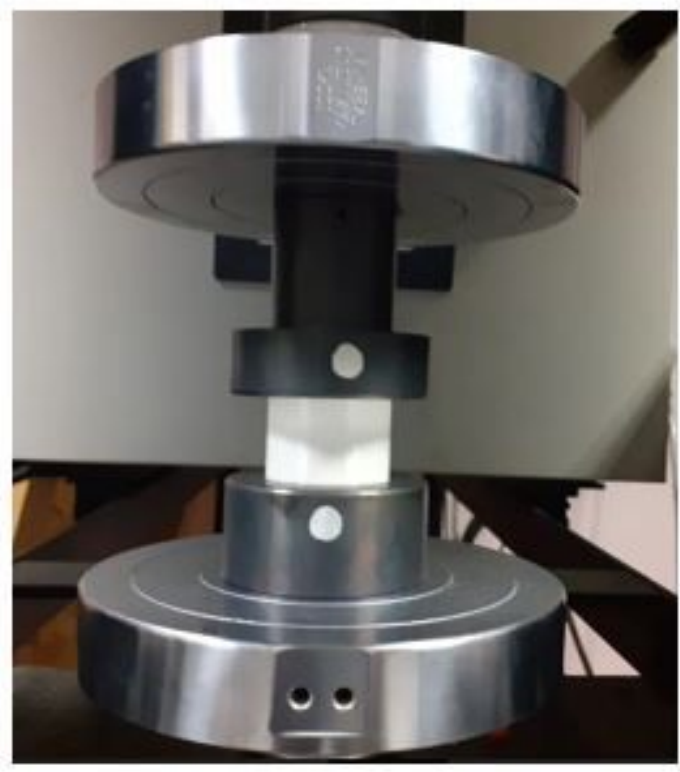

Figure 3

Experimental setup of compression test

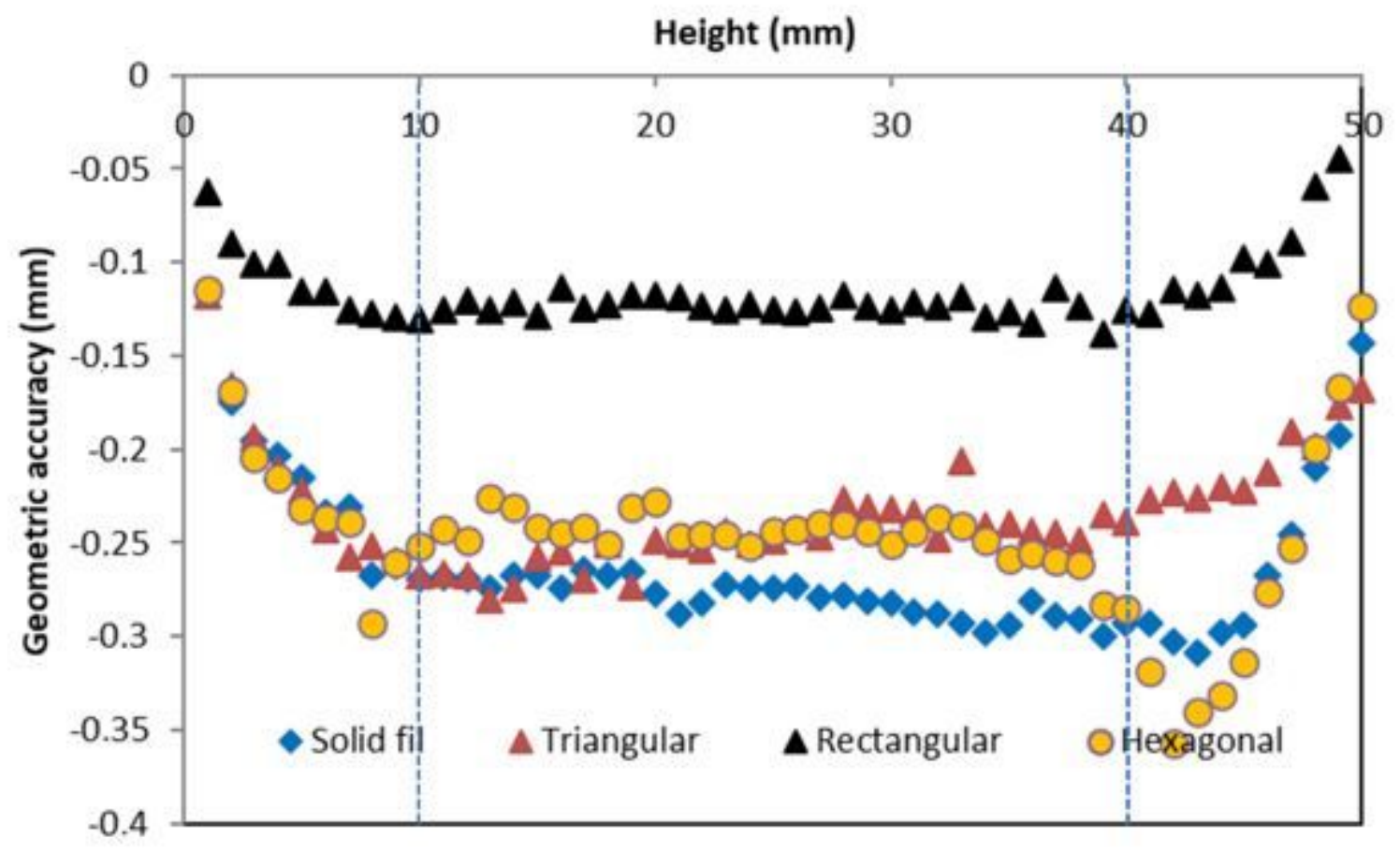

Figure 4

Geometric accuracy results for nylon with different fill patterns 


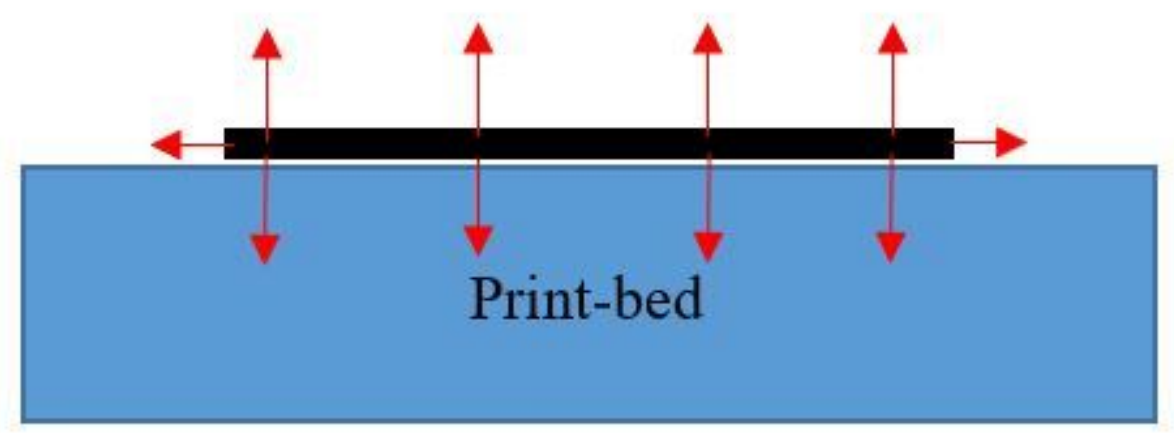

\section{Figure 5}

Shirinkage during printing of the first layer

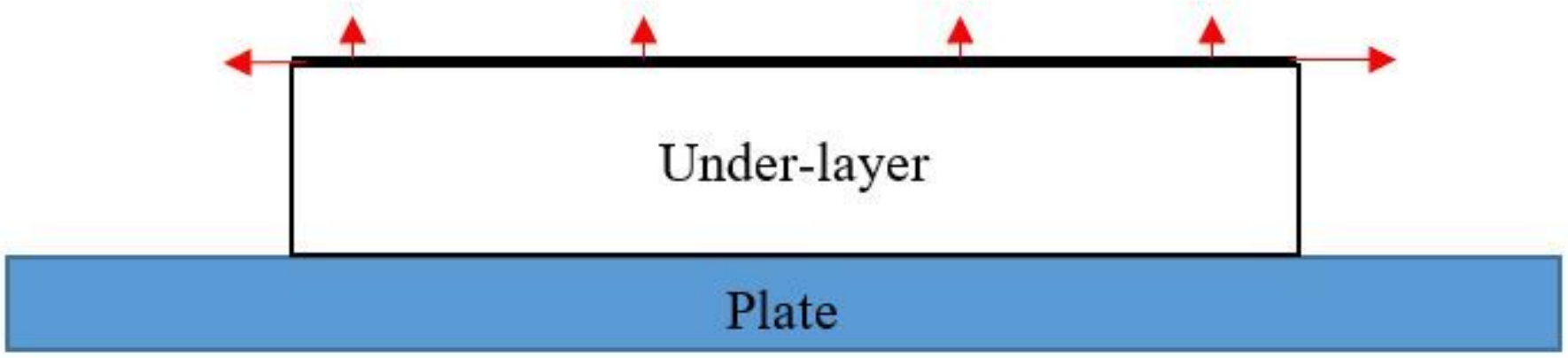

Figure 6

Shirinkage during printing of the last layer
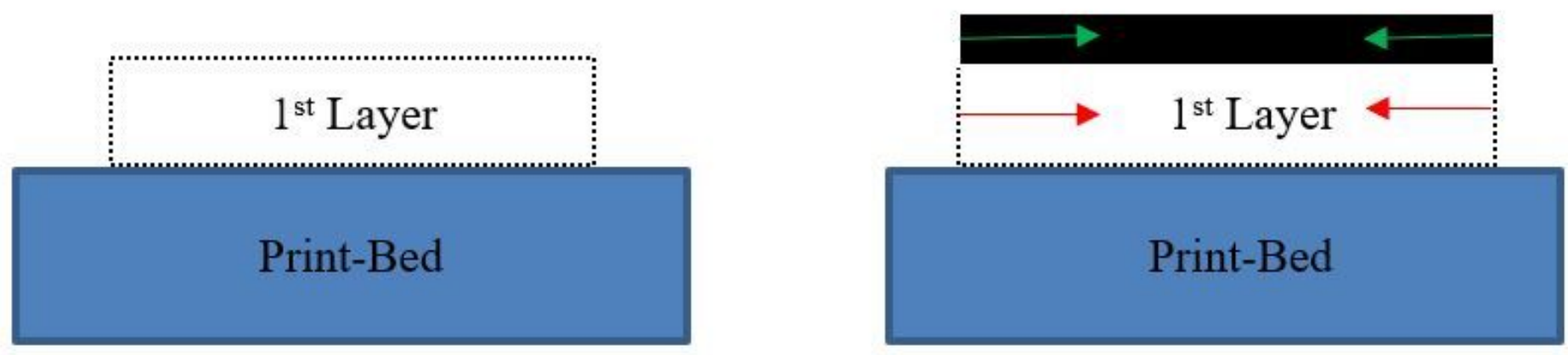

Figure 7

Cumulative shrinkage 


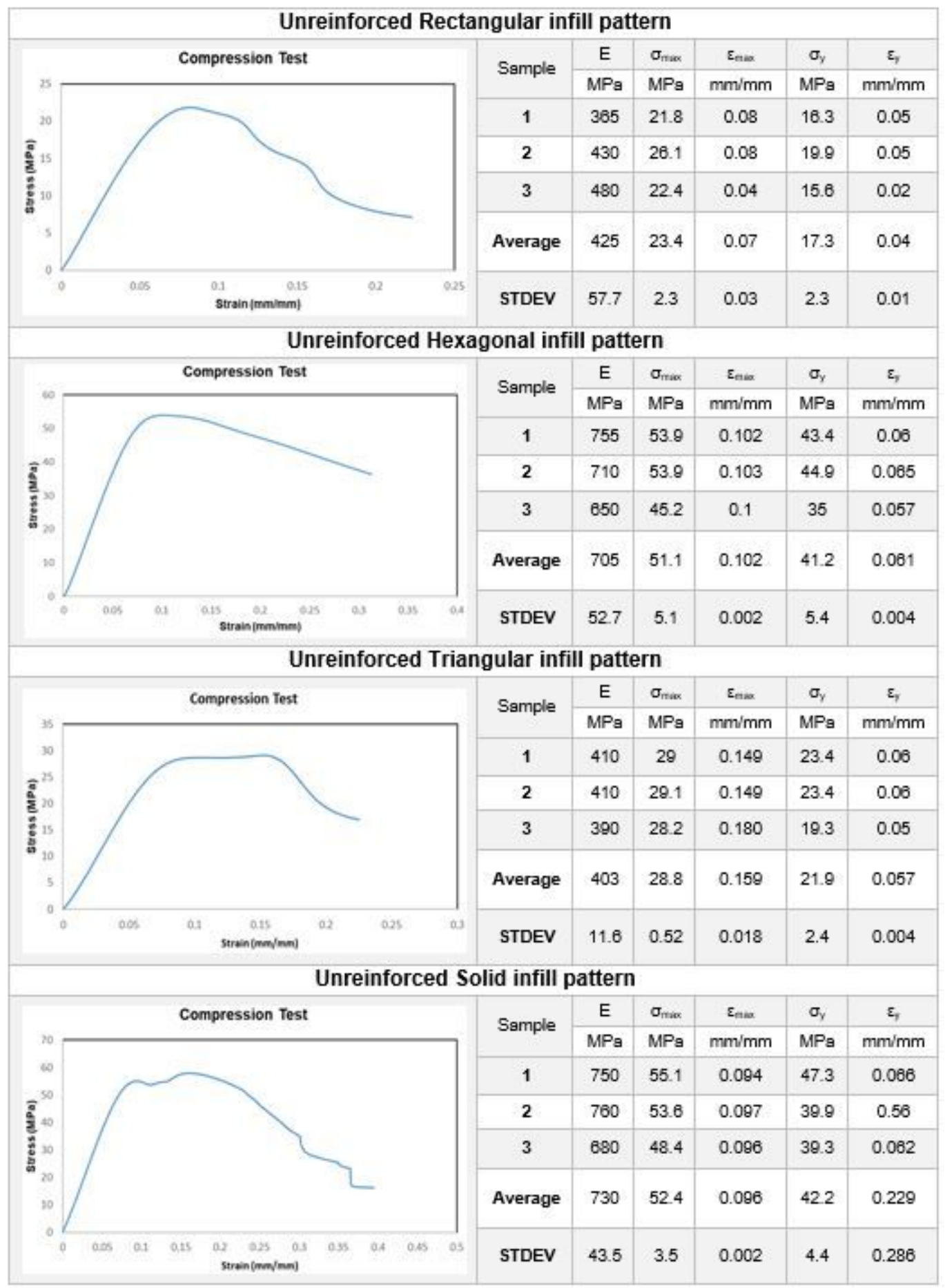

\section{Figure 8}

Compression results for nylon with different infill patterns 


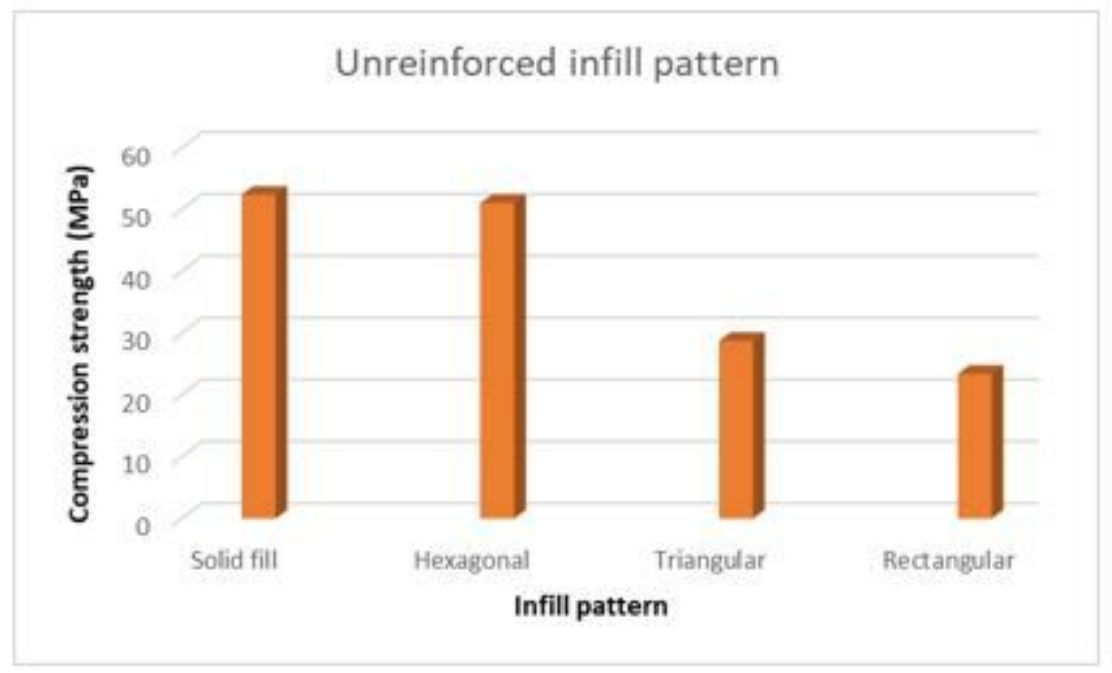

Figure 9

Compression strength of the different infill patterns

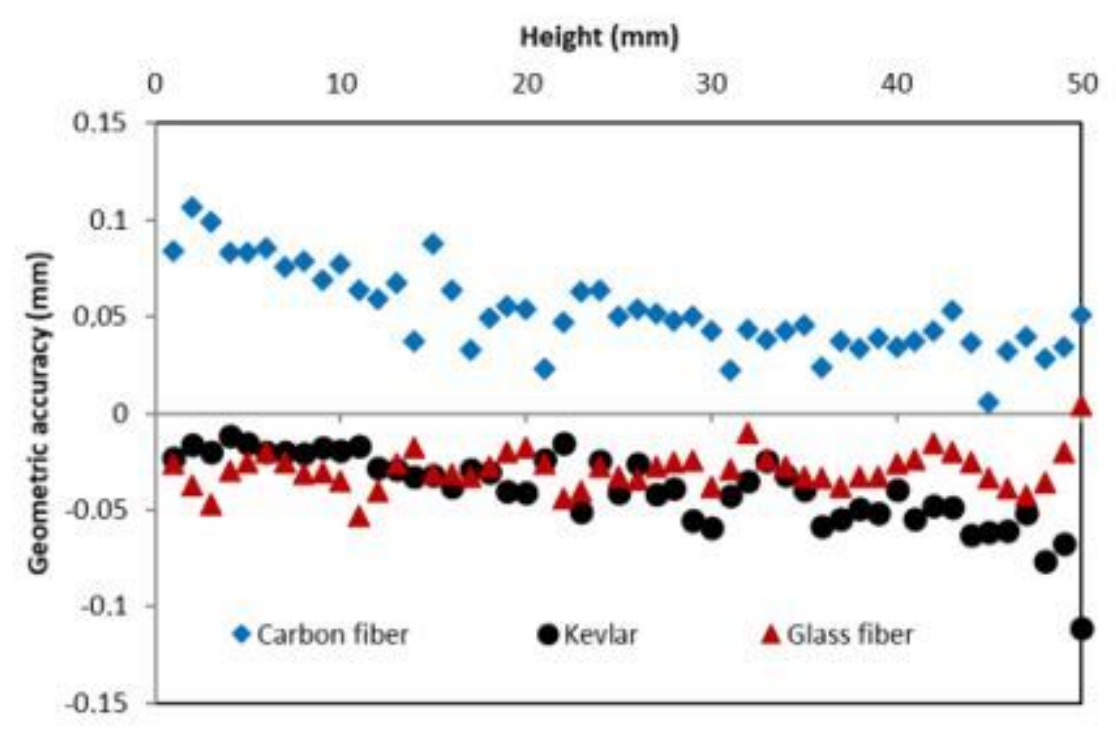

Figure 10

Geometric accuracy results for nylon with different reinforcements 


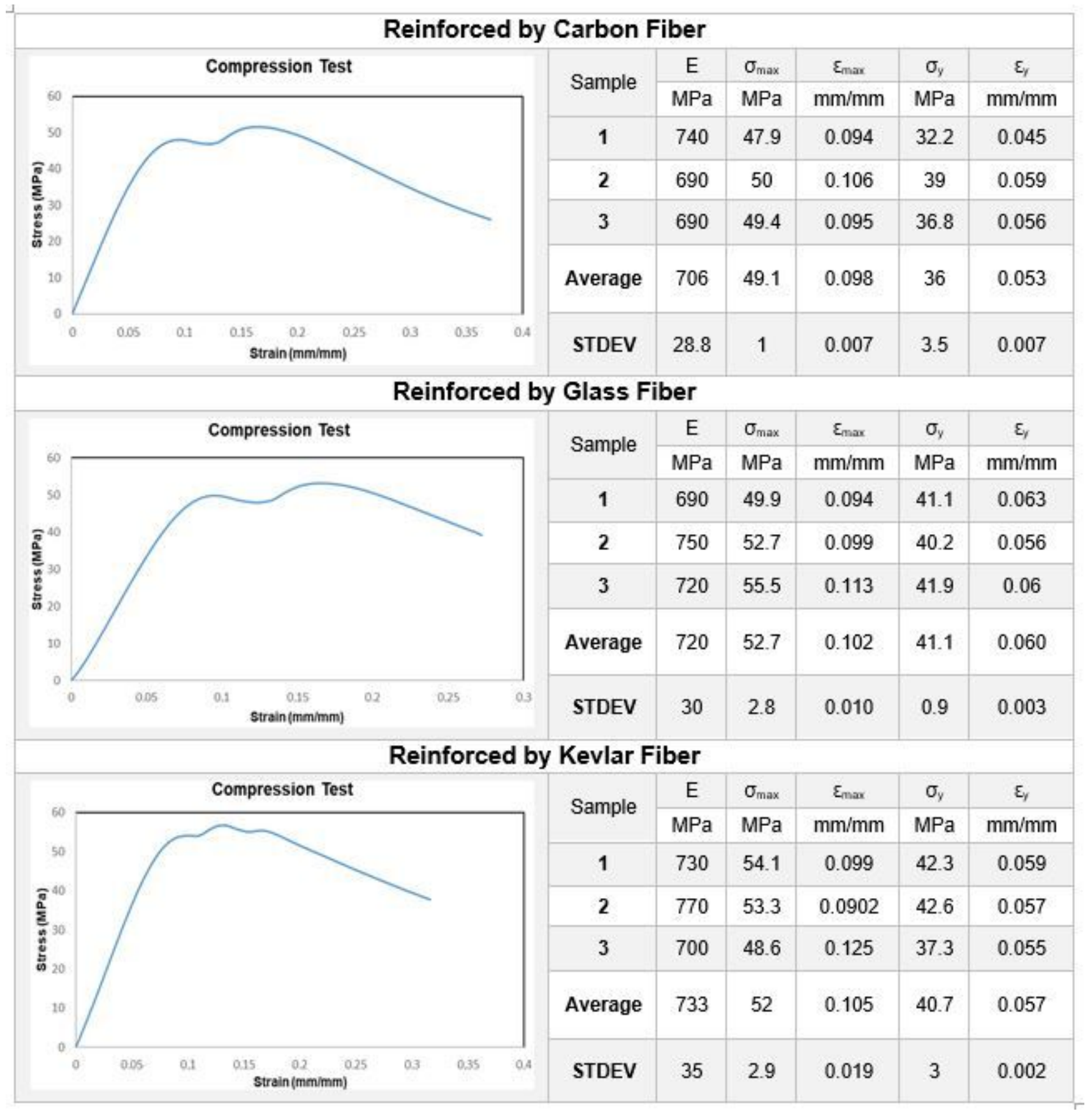

Figure 11

Compression results for nylon with different reinforcements 


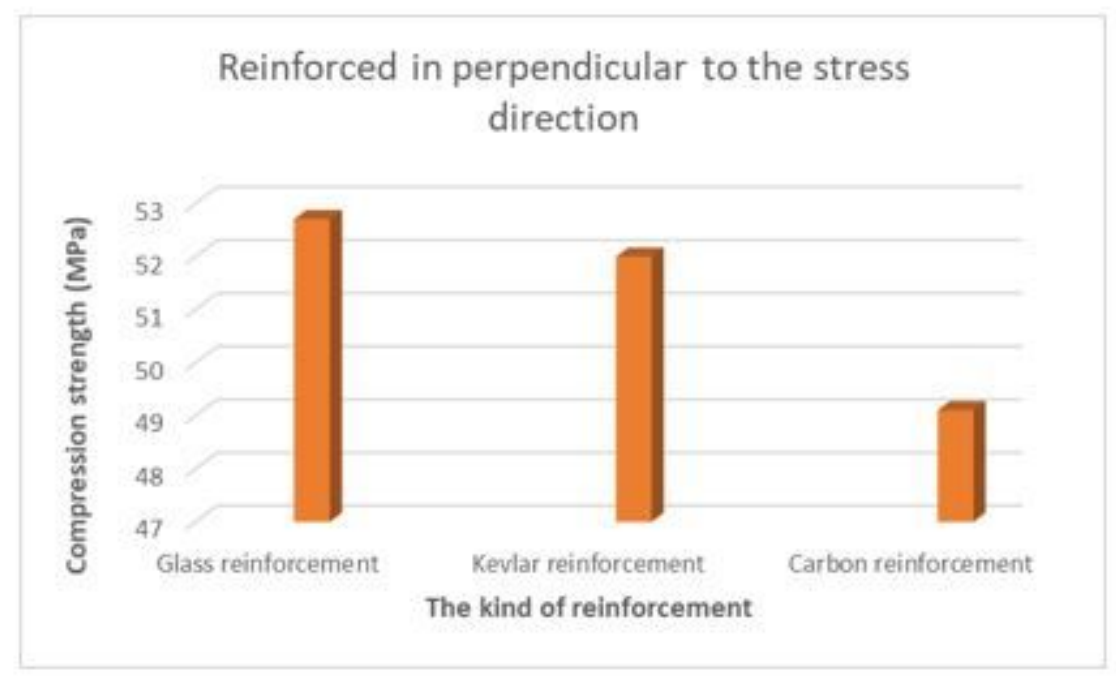

\section{Figure 12}

The effect of the different reinforcements on the compression strength (reinforcing, perpendicular to the stress direction)
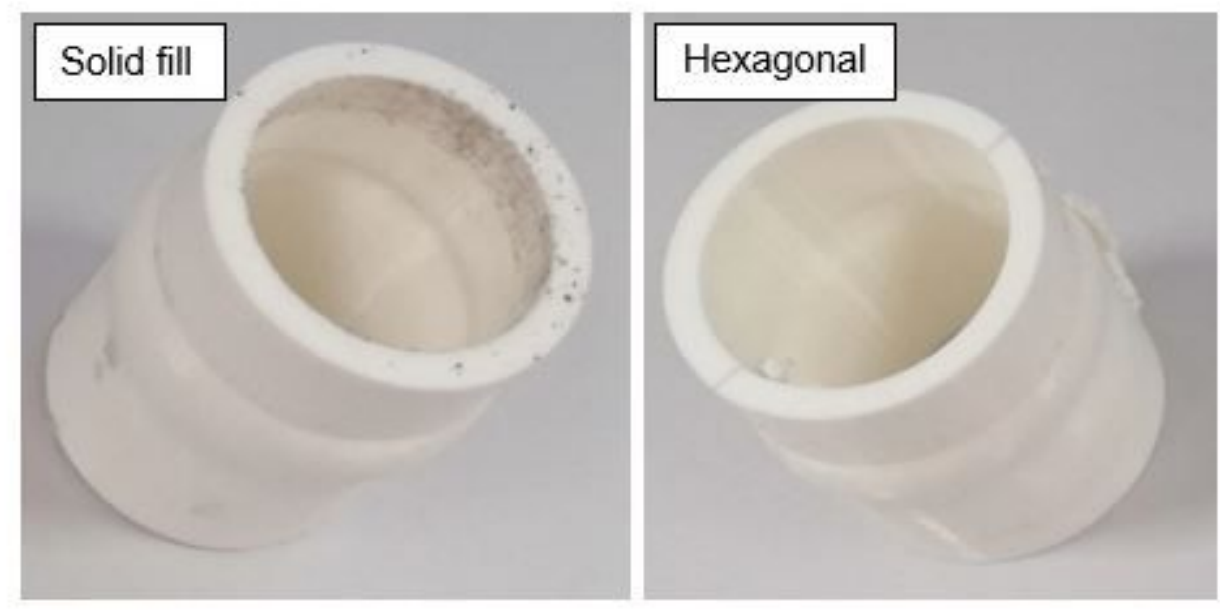

\section{Rectangular}

\section{Figure 13}

Macroscopic observation of tubes after compression tests 